\title{
НЕПЕРЕНОСИМОСТЬ КОНСЕРВАНТОСОДЕРЖАЩИХ ГЛАЗНЫХ КАПЕЛЬ ПРИ ГЛАУКОМЕ: ТРУДНОСТИ ДИАГНОСТИКИ, СЛОЖНОСТИ ЛЕЧЕНИЯ
}

М. А. Фролов ${ }^{1}$, К. А. Казакова ${ }^{1,2}$, Г. Н. Душина' ${ }^{1}$ А. М. Фролов ${ }^{1}$, П. А. Гончар ${ }^{1}$

1 Российский университет дружбы народов, Москва, Россия

${ }_{2}^{2}$ Многопрофильный медицинский холдинг «СМ-Клиника», Москва, Россия

В клинику поступил пациент с диагнозом OD о/у глаукома 1а. OS оперированная о/у глаукома ІІа. Состояние глазной поверхности расценено как токсико-аллергический конъюнктивит на фоне применения бримонидина 0,15\%. Проведена замена бримонидина 0,15\% на неселективный $\beta$-блокатор 0,5\% и назначены стероиды местно. На фоне отмены стероидов было отмечено частичное возобновление симптомов в виде умеренно выраженных гиперемии и отека конъюнктивы, что было расценено уже как непереносимость консерванта. Было решено заменить $\beta$-блокатор на бесконсервантную форму под регулярным контролем уровня ВГД, дополнительно рекомендованы слезозаменители, не содержащие консервантов. При следующем визите отмечено повышение ВГД выше толерантного, назначена безконсервантная форма комбинированного гипотензивного средства (аналог простагландина 0,005\% с неселективным $\beta$-блокатором 0,5\%) под контролем уровня ВГД. Неправильная постановка диагноза вначале лечения усугубила состояние глазной поверхности. Применение препаратов без консерванта благоприятно влияет на поверхность роговицы и повышает комплаентность пациентов. Ключевые слова: глаукома, консервант, бесконсервантная форма препарата, бримонидин, аллергическая реакция

Вклад авторов: М. А. Фролов - планирование исследования, анализ и интерпретация данных; К. А. Казакова, Г. Н. Душина, А. М. Фролов, П. А. Гончар - планирование исследования, анализ литературы, сбор, анализ и интерпретация данных, подготовка черновика рукописи.

Соблюдение этических стандартов: пациент подписал добровольное информированное согласие на участие в исследовании и публикацию данных.

$\bowtie$ Для корреспонденции: Ксения Александровна Казакова

ул. Миклухо-Маклая, д. 6, г. Москва, 117198; ponomareva_kseni@mail.ru

Статья получена: 26.12.2019 Статья принята к печати: 09.01.2020 Опубликована онлайн: 26.01.2020

DOI: $10.24075 /$ vrgmu.2020.005

\section{INTOLERANCE OF PRESERVATIVE-CONTAINING EYE DROPS IN A GLAUCOMA PATIENT: DIAGNOSTIC AND THERAPEUTIC CHALLENGES}

Frolov MA ${ }^{1}$, Kazakova KA ${ }^{1,2}$, Dushina $\mathrm{GN}^{1}$, Frolov $\mathrm{AM}^{1}$, Gonchar PA ${ }^{1}$

${ }^{1}$ Peoples' Friendship University of Russia, Moscow, Russia

${ }^{2}$ Multiprofile Clinic "SM-Clinic", Moscow, Russia

A patient presented to our clinic with stage la open-angle glaucoma of the right eye and stage lla surgically corrected open-angle glaucoma of the left eye. The condition of the ocular surface was interpreted as toxic/allergic conjunctivitis provoked by brimonidine $0.15 \%$. Brimonidine was substituted with non-selective $0.5 \%$; additionally, topical steroids were prescribed. After steroids were discontinued, some of the symptoms came back, including moderate hyperemia and conjunctival edema, which was interpreted as intolerance to a preservative contained in the eye drops. A decision was made to switch from the $\beta$-blocker to its preservative-free formulation; regular IOP monitoring was continued. IOP measured during the next visit was above tolerated, so a preservative-free form of the ocular hypotensive combination drug (an analog of prostaglandin 0.005\% with non-selective $\beta$-blocker $0.5 \%$ ) was introduced to the regimen, with further IOP monitoring. Because the initial diagnosis was wrong, damage to the ocular surface had been aggravated by inadequate therapy. Preservative-free hypotensive eye drops are beneficial for the corneal surface and have a positive effect on a patient's adherence to the regimen.

Keywords: glaucoma, preservative, brimonidine, preservative-free form, allergic reactions

Author contribution: Frolov MA — study planning; data analysis and interpretation; Kazakova KA, Dushina GN, Frolov AM, Gonchar PA — study planning; literature analysis; data acquisition, analysis and interpretation; manuscript preparation.

Compliance with ethical standards: the patient gave informed consent to participate in the study and for publication of its results

$\triangle$ Correspondence should be addressed: Kseniya A. Kazakova

Miklouho-Maclay, 6, Moscow, 117198; ponomareva_kseni@mail.ru

Received: 26.12.2019 Accepted: 09.01.2020 Published online: 26.01.2020

DOI: $10.24075 /$ brsmu.2020.005

Основным методом снижения внутриглазного давления (ВГД) остается местная гипотензивная терапия. До 60-80\% пациентов с глаукомой получают местное лечение в виде ежедневных инстилляций гипотензивных препаратов [1]. Такая терапия является длительной, чаще пожизненной, в ряде случаев используют комбинацию нескольких гипотензивных препаратов.

На сегодняшний день выработан определенный алгоритм назначения гипотензивной терапии. Препаратами первого выбора, как правило, являются аналоги PGF2 $\alpha$, так как они наиболее эффективно снижают уровень ВГД от исходного, а также обладают нейропротективными свойствами. При отсутствии достижения индивидуального целевого офтальмотонуса рекомендовано применение простамидов (биматопроста 0,03\%). При недостаточном снижении ВГД возможно добавление ингибиторов карбоангидразы. Следующим этапом лечения, при отсутствии желаемого гипотензивного эффекта, является применение фиксированных комбинаций (ФК), среди которых наиболее результативно сочетание однократной инстилляции биматопроста с тимололом [2].

Таким образом, в арсенале офтальмологов для лечения глаукомы имеется большой выбор гипотензивных препаратов различных фармакологических групп, однако все они могут вызывать те или иные побочные эффекты, которые связаны как непосредственно с активным компонентом гипотензивного средства (действующим веществом), так и с консервантом, входящим в подавляющее большинство глазных капель [3]. 
В последние годы большое количество отечественных и зарубежных исследований посвящено анализу частоты патологии глазной поверхности у пациентов с первичной глаукомой и изучению воздействия консервантов на поверхность глаза [4, 5-9]. Убедительно доказано, что консерванты приводят к уменьшению плотности бокаловидных клеток и, как следствие, к недостаточности муцинового слоя слезной пленки; нарушают структуру липидного слоя, в результате чего увеличивается испарение влаги и повышается осмолярность прероговичной слезной пленки; оказывают цитотоксический эффект на эпителиоциты конъюнктивы и роговицы, вызывают кератинизацию и воспалительную инфильтрацию в области лимба (влияние консервантов при глаукоме), индуцируют повышение уровня цитокинов и поддерживают иммуно-воспалительную реакцию в конъюнктиве (провоспалительная готовность) $[1,5,7,10]$.

Однако патологические изменения глазной поверхности могут быть вызваны и непосредственным воздействием фрармакологического агента гипотензивного препарата. Изучены механизмы развития роговичноконъюнктивального ксероза на фоне инстилляции $\beta$-блокаторов - снижение слезопродукции, а также местное анестетическое действие на эпителий, приводящее к снижению стимулирования базальной слезопродукции и продукции муцинов бокаловидными клетками конъюнктивы при повреждении эпителия глазной поверхности [5].

Немаловажно, что токсико-аллергические реакции на применение гипотензивных препаратов могут развиваться как сразу после начала применения, так и в более поздние сроки, что затрудняет диагностику и в ряде случаев служит причиной необоснованного назначения лекарственных средств (антибактериальных, противовирусных, нестероидных противовоспалительных препаратов (НПВП) и др.), что в свою очередь приводит к дополнительному ухудшению состояния глазной поверхности. Так, в описанных случаях аллергической реакции на селективный $\alpha_{2}$-адреномиметик бримонидин средняя продолжительность терапии до наступления аллергической реакции составила от 4 до 15 месяцев [11]

Лечение пациентов с непереносимостью консервантосодержащих глазных капель сопровождается рядом сложностей:

- непереносимость гипотензивных препаратов вызывает необходимость замены лекарственного средства, часто неоднократной, что требует от пациента дополнительных расходов на лечение;

- при развитии синдрома сухого глаза, спровоцированного консервантами глазных капель, необходимо назначение препаратов искусственной слезы, также не содержащих консерванты;

- при недостаточном снижении ВГД В случаях, когда требуется применение нескольких гипотензивных препаратов, необходимо проведение аллергопроб на сенсибилизацию к глазным каплям [11];

- в случаях развившейся токсико-аллергической реакции, роговично-конъюнктивального ксероза и при невозможности отказа от гипотензивных капель, содержащих консерванты, приходится назначать дополнительную терапию: противоаллергическую системную и местную, стероидные препараты, которые в свою очередь могут вызвать повышение ВГД, репаративные средства. При этом также могут возникать аллергические реакции на консерванты, содержащиеся в назначаемых лекарственных средствах;
- в некоторых случаях из-за поливалентной аллергии подобрать гипотензивный препарат не удается и приходится прибегать к оперативному лечению.

В настоящее время В РФ зарегистрировано несколько безконсервантных гипотензивных препаратов. Положительное влияние не содержащих консерванта гипотензивных средств на глазную поверхность по сравнению с аналогичными консервантосодержащими препаратами доказано в многочисленных исследованиях отечественных и зарубежных авторов [1, 4, 12-18], однако их широкое применение затруднено рядом фракторов:

- в РФ зарегистрировано всего семь гипотензивных глазных капель, не содержащих консервантов;

- большинство гипотензивных препаратов, не содержащих консервант, имеет в своем составе $\beta$-блокатор. Известно, что гипотензивный эффект $\beta$-блокаторов со временем снижается, что требует назначения дополнительных препаратов. Кроме того, применение неселективных $\beta$-блокаторов ограничено их системными побочными эффектами.

\section{Описание клинического случая}

Показательно следующее клиническое наблюдение. Пациент К., 67 лет, проживающий в отдаленном регионе РФ, обратился с жалобами на покраснение обоих глаз, жжение, слезотечение в течение полугода (см. рис.).

Из анамнеза: пациент с диагнозом OD о/у глаукома 1 . OS оперированная о/у глаукома Ila. В январе 2017 г. проведена непроникающая глубокая склерэктомия с имплантацией клапанного дренажа Ahmed на левом глазу. Дополнительно назначены инстилляции бримонидина в оба глаза. Данных об уровне ВГД на левом глазу перед операцией нет. В мае 2017 г. обратился к офтальмологу по месту жительства с жалобами на выраженное покраснение обоих глаз. Обследован. Диагностирован блефароконъюнктивит. Посев с конъюнктивы патологической микрофлоры не выявил. Обнаружены клещи рода Demodex. Назначены противодемодекозная терапия и субконъюнктивные инъекции гентамицина с дексаметазоном, на фоне которых «покраснение» глаз быстро прошло. Однако в течение следующих нескольких месяцев отмечалось периодическое покраснение глаз. Состояние пациента ухудшилось с начала ноября 2017 г. Многократно обращался к офтальмологам в различные

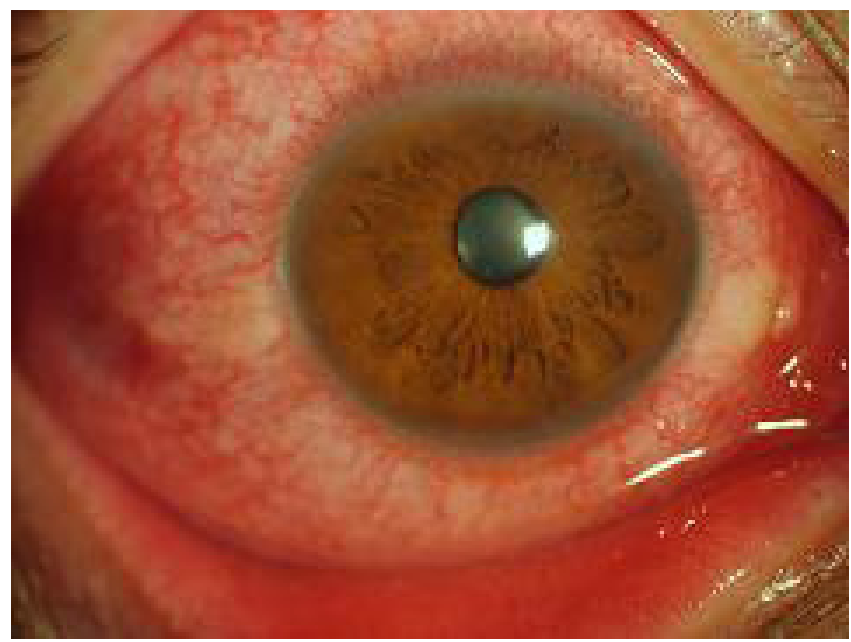

Рис. Правый глаз. Смешанная инъекция глазного яблока. Фолликулы и умеренная отечность конъюнктивы нижнего века 
учреждения по месту проживания и в соседние населенные пункты. Повторно взят посев с конъюнктивы на флору; рост патологической микрофлоры не обнаружен. При повторном исследовании на демодекоз обнаружены единичные имаго. В мазке с конъюнктивы было выявлено много лейкоцитов. Местно назначены: антисептики, антибиотики различных групп, препараты интерферона и индуктор его синтеза, антигистаминные препараты, кортикостероиды, кератопротекторы, гигиена век. Эффекта от лечения отмечено не было.

Состояние пациента при обращении (декабрь 2017 г.): $\mathrm{MKO3} \mathrm{OD=0,9,} \mathrm{MKO3} \mathrm{OS} \mathrm{=} \mathrm{0,8.} \mathrm{ВГД} \mathrm{(пневмотонометрия)}$ OD - 18-19 мм рт. ст., OS - 20-21 мм рт. ст. При осмотре кожа век гиперемирована, веки отечны, слезные органы не изменены, слезотечение. Выраженная гиперемия конъюнктивы во всех отделах, выраженный отек конъюнктивы в сводах, фолликулы конъюнктивы век и сводов, отделяемое скудное в виде хлопьев. На роговице обоих глаз старые точеные единичные субэпителиальные помутнения. ВГД пальпаторно - в пределах нормы. Состояние глазной поверхности расценено как токсикоаллергический конъюнктивит на фоне применения бримонидина 0,15\%.

\section{Обсуждение клинического случая}

Замена бримонидина 0,15\% на неселективный $\beta$-блокатор 0,5\% и назначение стероидов местно на короткий срок под контролем ВГД привели к положительной субъективной и объективной динамике, однако на фоне отмены стероидов было отмечено частичное возобновление симптомов в виде умеренно выраженных гиперемии и отека конъюнктивы, что было расценено уже как непереносимость консерванта. Было решено заменить $\beta$-блокатор на бесконсервантную форму под регулярным контролем уровня ВГД, дополнительно рекомендованы слезозаменители, не содержащие консервантов. Выбор препарата обусловлен отсутствием в городе проживания пациента каких-либо других бесконсервантных гипотензивных препаратов.

Пациент длительно (более 9 месяцев) на контрольный осмотр не приезжал, ВГД контролировал по месту жительства. Обратился повторно в октябре 2018 г. с жалобами на ухудшение зрения левого глаза. Со слов пациента и согласно имеющимся на руках результатам тонометрии по Маклакову, уровень ВГД на оперированном глазу варьировал от 15 до 23 мм рт. ст. При обращении Vis OS = 0,2, MKO3 = 0,5. При осмотре веки не изменены, слезотечение отсутствует, конъюнктива спокойна во всех отделах. При офтальмоскопии OS диск зрительного нерва значительно осветлен, обнаружена краевая экскавация. По данным автоматической статической периметрии выявлены сужение поля зрения с назальной стороны до 30 , множественные абсолютные скотомы в центральной зоне. Уровень ВГД: OD - 15 мм рт. ст., OS - 24 мм рт. ст.

В связи с отрицательной динамикой остроты зрения левого глаза и повышением ВГД до 24 мм рт. ст. рекомендована повторная антиглаукомная операция, временно усилен гипотензивный режим. Назначена безконсервантная форма комбинированного гипотензивного средства (аналог простагландина 0,005\% с неселективным $\beta$-блокатором 0,5\%) под контролем уровня ВГД. В связи с отсутствием препарата в аптечной сети по месту проживания пациент вынужден закупать лекарственное средство в другом городе.

Повторное оперативное вмешательство по месту жительства пациента проведено не было. При обращении в январе 2019 г. периметрия и состояние диска зрительного нерва - без отрицательной динамики, ВГД ОD - 16 мм рт. ст., OS - 19 мм рт. ст. Однако пациент жаловался на периодическое покраснение глаз, в том числе на фоне применения слезозаменителей, что можно расценивать как побочную реакцию на инстилляцию аналога простагландина. Контроль ВГД по месту жительства показал периодическое его повышение на левом глазу до 22-24 мм рт. ст.

В связи с непереносимостью консервантосодержащих гипотензивных препаратов, отсутствием стойкого гипотензивного эффекта от назначенного лечения, сложностью ведения пациента в связи с проживанием в отдаленном регионе пациенту настоятельно рекомендована повторная антиглаукомная операция.

\section{ВЫВОДЫ}

Неправильная трактовка этиологии конъюнктивита/ блефароконъюнктивита приводит к полипрагмазии. При этом назначение нескольких лечебных препаратов в дополнение к основному гипотензивному усугубляет состояние глазной поверхности и значительно удорожает процесс лечения. Отсутствие бесконсервантных форм препаратов всех используемых в лечении глаукомы фармакологических групп в ряде случаев может приводить к прогрессированию заболевания. А невозможность отказа от использования консервантосодержащих глазных капель в связи с недостаточным гипотензивным эффектом на фоне применения бесконсервантных форм значительно снижает качество жизни пациента, уровень его комплаентности, а также может служить причиной проведения хирургического вмешательства.

\section{Литература}

1. Астахов С. Ю., Ткаченко Н. В. Тафрлотан - первый аналог простагландина-F2 $\alpha$ без консервантов: преимущества в лечении больных первичной открытоугольной глаукомой. Офттальмологические ведомости. 2016; 9 (2): 59-68.

2. Егоров А. Е., Глазко Н. Г., Мовсисян А. Б. Гипотензивная и нейропротективная терапия глаукомы: реалии и перспективы. Русский медицинский журнал. Клиническая офттальмология. 2019; 19 (3): 128-36.

3. Яни Е. В., Селиверстова К. Е. Токсико-аллергический конъюнктивит у пациентов с первичной глаукомой на фоне медикаментозного гипотензивного лечения. Фарматека.
2016; 20 (333): 12-14.

4. Еричев В. П., Амбарцумян К. Г., Федоров А. А. Клиникоморфологические доказательства влияния консервантов на поверхность глаза при первичной открытоугольной глаукоме. Национальный журнал глаукома. 2014; 13 (4): 13-22.

5. Бржеский В. В., Радхуан М. Глаукома и синдром «сухого глаза». Офтальмологические ведомости. 2014; 7 (2): 37-49.

6. Сафонова Т. Н., Федоров А. А., Забегайло А. О., Егорова Г. Б., Митичкина Т. С. Лечение синдрома "сухого глаза» при первичной глаукоме. Национальный журнал глаукома. 2015; 14 (4): 36-43. 
7. Еричев В. П., Амбарцумян К. Г. Особенности гипотензивной терапии больных глаукомой препаратами, не содержащими консервантов. Практическая медицина. 2012; 4 (59): 194-6.

8. Erb C, Gast U, Schremmer D. German register for glaucoma patients with dry eye. I. Basic outcome with respect to dry eye. Graefe's Arch Clin Exp Ophthalmol. 2008; 246 (11): 1593-601.

9. Leung EW, Medeiros FA, Weinreb RN. Prevalence of ocular surface disease in glaucoma patients. J Glaucoma. 2008; 17 (5): 350-5.

10. Астахов С. Ю. Грабовецкий В. Р., Неседова Д. М., Ткаченко Н. В. Преимущества и недостатки гипотензивных капель без консерванта. Офтальмологические ведомости. 2011; 4 (20): 95-7.

11. Штейнер И., Бранчевский С. Проблемы дифференциальной диагностики отсроченной аллергической реакции у пациентов, получающих местное гипотензивное лечение глаукомы. Врач. 2016; (12): 62-4.

12. Алексеев И. Б., Королева И. А. Бесконсервантные гипотензивные препараты: преимущества терапии. Русский медицинский журнал. Клиническая офтальмология. 2019; 19 (3): 137-42.

13. Антонов А. А., Козлова И. В., Митичкина Т. С., Ведмеденко И. И. Бесконсервантная терапия глаукомы у пациентов, перенесших кераторефракционные операции. Русский

\section{References}

1. Astahov SYu, Tkachenko NV. Taflotan - pervyj analog prostaglandina-F2 $\alpha$ bez konservantov: preimushchestva $\vee$ lechenil bol'nyh pervichnoj otkrytougol'noj glaukomoj. Oftal'mologicheskie vedomosti. 2016; 9 (2): 59-68.

2. Egorov AE, Glazko NG, Movsisyan AB. Gipotenzivnaya nejroprotektivnaya terapiya glaukomy: realii i perspektivy. Russkij medicinskij zhurnal. Klinicheskaya oftal'mologiya. 2019; 19 (3): 128-36.

3. Yani EV, Seliverstova KE. Toksiko-allergicheskij kon"yunktivit u pacientov s pervichnoj glaukomoj na fone medikamentoznogo gipotenzivnogo lecheniya. Farmateka. 2016; 20 (333): 12-14.

4. Erichev VP, Ambarcumyan KG, Fedorov A.A. Klinikomorfologicheskie dokazatel'stva vliyaniya konservantov na poverhnost' glaza pri pervichnoj otkrytougol'noj glaukome. Nacional'nyj zhurnal glaukoma. 2014; 13 (4): 13-22.

5. Brzheskij W, Radhuan M. Glaukoma i sindrom "suhogo glaza". Oftal'mologicheskie vedomosti. 2014; 7 (2): 37-49.

6. Safonova TN, Fedorov AA, Zabegajlo AO, Egorova GB, Mitichkina TS Lechenie sindroma "suhogo glaza" pri pervichnoj glaukome. Nacional'nyj zhurnal glaukoma. 2015; 14 (4): 36-43.

7. Erichev VP, Ambarcumyan KG. Osobennosti gipotenzivnoj terapii bol'nyh glaukomoj preparatami, ne soderzhashchimi konservantov. Prakticheskaya medicina. 2012; 4 (59): 194-6.

8. Erb C, Gast U, Schremmer D. German register for glaucoma patients with dry eye. I. Basic outcome with respect to dry eye. Graefe's Arch Clin Exp Ophthalmol. 2008; 246 (11): 1593-601.

9. Leung EW, Medeiros FA, Weinreb RN. Prevalence of ocular surface disease in glaucoma patients. J Glaucoma. 2008; 17 (5): 350-5.

10. Astahov Syu, Graboveckij VR, Nefedova DM, Tkachenko NV. Preimushchestva i nedostatki gipotenzivnyh kapel' bez медицинский журнал. Клиническая офтальмология. 2019; 19 (3): $165-70$

14. Лоскутов И. А., Корнеева А. В. Бесконсервантная форма фиксированной комбинации биматопроста и тимолола в повышении комплаенса и эффективности лечения пациентов с первичной открытоугольной глаукомой Российский офтальмологический журнал. 2018; 11 (2): 95-101.

15. Онищенко А. Л., Димаксян М. В., Колбаско А. В., Жилина Н. М. Лечение первичной открытоугольной глаукомы $\beta$-ксололом без консерванта: оценка гипотензивного эффекта и глазной поверхности. Вестник офтальмологии. 2015; 131 (20): 76-80.

16. Егоров Е. А. Новые формы селективных $\beta$-блокаторов в лечении глаукомы. Клиническая офтальмология. 2014; 14 (3): 131-5.

17. Bourne R, Kaarniranta K, Lorenz K, Traverso CE, Vuorinen J, Ropo A. Changes in ocular signs and symptoms in patients switching from bimatoprost-timolol to tafluprost-timolol eye drops: an open-label phase IV study. BMJ Open. 2019; 9 (4).

18. Pillunat LE, Eschstruth $\mathrm{P}$, Häsemeyer $\mathrm{S}$, Thelen U, Foja C, Leaback $R$, et al. Preservative-free bimatoprost $0.03 \%$ in patients with primary open-angle glaucoma or ocular hypertension in clinical practice. Clin Ophthalmol. 2016; 12 (10): 1759-65.

konservanta. Oftal'mologicheskie vedomosti. 2011; 4 (20): 95-97.

11. Shtejner I, Branchevskij S. Problemy differencial'noj diagnostiki otsrochennoj allergicheskoj reakcii u pacientov, poluchajushhih mestnoe gipotenzivnoe lechenie glaukomy. Vrach. 2016; (12): 62-4.

12. Alekseev IB, Koroleva IA. Beskonservantnye gipotenzivnye preparaty: preimushhestva terapii. Russkij medicinskij zhurnal. Klinicheskaja oftal'mologija. 2019; 19 (3): 137-42.

13. Antonov AA, Kozlova IV, Mitichkina TS, Vedmedenko II. Beskonservantnaya terapiya glaukomy u pacientov, perenesshih keratorefrakcionnye operacii. Russkij medicinskij zhurnal. Klinicheskaya oftal'mologiya. 2019; 19 (3): 165-70.

14. Loskutov IA, Korneeva AV. Beskonservantnaya forma fiksirovannoj kombinacii bimatoprosta i timolola $v$ povyshenii komplaensa i effektivnosti lecheniya pacientov s pervichnoj otkrytougol'noj glaukomoj. Rossijskij oftal'mologicheskij zhurnal. 2018: 11 (2): 95-101.

15. Onishchenko AL, Dimaksyan MV, Kolbasko AV, ZHilina NM Lechenie pervichnoj otkrytougol'noj glaukomy $\beta$-ksololom bez konservanta: ocenka gipotenzivnogo effekta i glaznoj poverhnosti. Vestnik oftal'mologii. 2015; 131 (20): 76-80.

16. Egorov EA. Novye formy selektivnyh $\beta$-blokatorov $\vee$ lechenii glaukomy. Klinicheskaya oftal'mologiya. 2014; 14 (3): 131-5.

17. Bourne R, Kaarniranta K, Lorenz K, Traverso CE, Vuorinen J, Ropo A. Changes in ocular signs and symptoms in patients switching from bimatoprost-timolol to tafluprost-timolol eye drops: an open-label phase IV study. BMJ Open. 2019; 9 (4).

18. Pillunat LE, Eschstruth $P$, Häsemeyer $S$, Thelen U, Foja C, Leaback $R$, et al. Preservative-free bimatoprost $0.03 \%$ in patients with primary open-angle glaucoma or ocular hypertension in clinical practice. Clin Ophthalmol. 2016; 12 (10): 1759-65. 